\title{
Gorodischer, Julián, y Marcos Vergara. 2015. Camino a Auschwitz y otras historias de resistencia. Buenos Aires: Emecé, 112 p.
}

\section{AlEJANDRA MERILES}

Universidad Nacional de Córdoba (Argentina)

https://orcid.org/0000-0001-7681-7090

doi: https://dx.doi.org/10.7238/dd.voig.391158

«Desde 1980, la pregunta no es si se puede representar el Holocausto en literatura, cine, y artes visuales, sino cómo» (Huyssen 2000, 65). Con este diagnóstico, Andreas Huyssen inicia un artículo sobre la historieta Maus, de Art Spiegelman, que presenta como literatura de la Shoá y documento de memoria pública. Para su argumentación retoma los conceptos analíticos de la teoría mimética de Theodor Adorno, demostrando que el uso experimental y autorreflexivo del lenguaje historietístico aleja esta obra de las críticas que se le puedan hacer a la industria cultural, bien pertinentes en el caso del resto del cómic estadounidense.

La deriva por los medios expresivos (el cómo) se justifica con una urgencia previa: el problema de la transmisión de los testimonios del horror nazi a las nuevas generaciones. En Maus, el hijo entrevista a su padre sobre el cautiverio en Auschwitz y luego recrea la historia escuchada, con su propio marcado del tiempo, insertando aclaraciones sostenidas por una investigación documental complementaria y añadiendo sus propias reacciones a esta reconstrucción pública de la historia familiar. El libro recibió un premio Pulitzer de categoría especial en 1992, de manera que su tratamiento quedó consagrado como periodístico. Así nació el género del cómic periodístico.

Camino a Auschwitz y otras historias de resistencia está guionada por un periodista que entrevista a sus parientes polacos y judíos para contar su huida del régimen nazi hacia la Argentina. Como migrante de tercera generación (el nieto de los llegados al país), recibe un legado narrativo nebuloso y lleno de omisiones típicas del relato mítico de refundación de un clan familiar. Muchos fragmentos le son susurrados o apenas insinuados. Cuando cumple cuarenta años (como el personaje del hijo en Maus), decide viajar a Cracovia y de allí a Auschwitz, buscando corroborar 
o corregir la historia de la tía abuela que quedó en Europa y falleció en ese campo de concentración. Por ello, el propio guionista describe su obra del siguiente modo:

No es un libro sobre el Holocausto, es apenas una escenografía para contar la memoria de una familia y qué hace esa familia con el secreto, con el tabú y con la transmisión del relato oral a través de las generaciones. (Gorodischer en Dell'Isola 2015)

Una maraña de líneas temporales atraviesa los tres capítulos: el viaje del guionista a su pueblo de origen en 2013, la vida de sus tías abuelas en el gueto de Auschwitz desde 1941, la resistencia judía organizada en Varsovia desde 1943, la entrevista con su tío abuelo en 2013 y con su tía abuela en 2005 y 2013, y el arresto de Adolf Eichmann en Argentina en 1960. Son las raíces del árbol familiar. Gorodischer las ordena de acuerdo a los tres protagonistas: Paie en «Camino a Auschwitz», Berl en «El partisano de Varsovia» y Luba en «El secuestro de Eichmann».

Este trabajo cronológico no resulta extraño ya que, mientras escribía los guiones de la historieta, Gorodischer preparaba su tesis de doctorado en ciencias de la comunicación (UBA, Argentina) sobre la crónica en el nuevo periodismo. La página de historieta le facilitó, entonces, exponer el mosaico de líneas narrativas, aclarando la ubicación espaciotemporal a través de cartuchos de texto y utilizando, entre otros recursos, un código cromático para diferenciar el pasado del presente. Solo la figuración del guionista parece indemne a los viajes en el tiempo. Su presencia cumple el rol de un director de orquesta, coordinando la unidad de un relato coral.

La preocupación del guionista por hacer primar la intención comunicativa y el apego al registro visual documentado lo llevó a elegir la compañía del dibujante Marcos Vergara. Gorodischer entendió que el dibujo también narra, y prefirió su «estilo como infantilizado», sus líneas claras, su capacidad de síntesis y una atención al detalle tal que «permitió que la época se manifieste» (Dell'Isola, 2015). Bibliotecólogo y archivólogo, Vergara tiene experiencia en la reconstrucción visual de hechos pasados por su participación en cómics históricos (por ejemplo, en Morir por el Che, de 2013, junto con el guionista Pablo Leguizamo), así como en el 
moldeado del ritmo de la vida cotidiana en obras costumbristas como Cena con amigos (2009) o Valizas (2012), junto con el guionista Rodolfo Santullo. De esta manera, la historieta les permitió cumplir con lo que sostenía Gorodischer que es el objetivo de toda novela gráfica realista: «expandir la imaginación visual» (Wamba Gaviña 2015, 7).

Este realismo experimental redobla su utilidad al remover, además de narrar, los sedimentos del imaginario social al que está inseparablemente vinculado. Huyssen $(2004,15)$ advierte que los recuerdos políticos que «están codificados en el consenso nacional se tornan clichés, [y] se han convertido en un nuevo desafío para la memoria viva». Entonces, retomando la cita inicial, ¿cómo narrar cuando hay una resistencia por parte de la memoria oficial misma? También Gorodischer (2015) se lo plantea:

Especialmente cuando el Holocausto es el telón de fondo, no hay lugar para despreciar o distorsionar el fenómeno en sí - según señaló el escritor israelí Etgar Keret- ¿ ¿Cuáles son los límites formales cuando el horror se narra en historieta?

Camino a Auschwitz se topó con estos límites y resistencias desde el momento en que fue publicado.

Inserto en el género de no ficción, el proyecto respetó la memoria histórica a través de una amalgama de textos verídicos pero unidos con la misma estrategia narrativa de una novela histórica. Graciela Wamba Gaviña nota los momentos en que la licencia imaginativa hace las uniones: la historia de Paie se sirve de Eichmann en Jerusalem, de Hannah Arendt, de Si esto es un hombre, de Primo Levi, y de La farmacia del gueto de Cracovia, de Tadeusz Pankiewicz. Los autores ficcionalizan su relación con el farmacéutico Pankiewicz y con Levi, hasta el punto de que las palabras que este último le dirige a una Paie enferma corresponden a las que dijo cuando fue trasladado desde el campo italiano de Fossoli al de Auschwitz (Wamba Gaviña 2015, 4). Así mismo, Luba solo acompañó a Eichmann desde el aeropuerto de Buenos Aires hasta Israel, pero no participó en el Operativo Garibaldi, y la reconstrucción ficcional del confinamiento, a su vez, se basa en el testimonio de Peter Z. Malkin en Eichmann en mis manos (Wamba Gaviña 2015, 10). 
La obra adolece de un aparato crítico o un prólogo que aclare esta estrategia narrativa. Si bien forma parte del contrato de lectura del género, no le quitaría mérito añadirlo.

Al contrario. Tal vez con la exposición de su fidelidad «al acontecimiento tal como se produjo, sin invención» (Dell'Isola 2015), y, siguiendo al cómicreportero Joe Sacco, respetando el hecho «como "verdad gráfica esencial" y que admite más permisos para trabajar la materia de los sueños, los mitos y las fantasías» (Gorodischer 2015) podría haberse evitado el malentendido que desencadenó una denuncia ante el INADI, organismo estatal argentino que condena la discriminación, la xenofobia y el racismo.

Previamente a su publicación en formato de libro, dos de los tres capítulos del cómic habían sido difundidos en revistas periodísticas digitales: «El secuestro de Eichmann» apareció en Anfibia y «Camino a Auschwitz» en Brando. De la tumultuosa escena onírica en esta última (correspondiente en la edición impresa a la página 42), un lector interpretó que había un tratamiento distorsivo del hecho, sea por inautenticidad factual o por odio antisemita. Gorodischer aclara:

El INADI concluyó que «el cómic denunciado, a los ojos del organismo no pretendió minimizar ni distorsionar lo que el Holocausto o Auschwitz representan». El perito que firma consideró que del análisis no podía deducirse que se haya incurrido en posturas discriminatorias para con la colectividad judía, dijo que cualquier referencia literaria a la verdad o la realidad es alusiva, habló del non-fiction como género instalado, desestimó la denuncia y exoneró el libro. (Dell'Isola 2015)

En una conferencia donde señala las similitudes entre la construcción de las memorias de las víctimas de la dictadura argentina y las de los bombardeos sobre ciudades alemanas durante la Segunda Guerra Mundial, Huyssen sostiene que hay «formas políticamente deseables de olvido [que] darán resultados que distorsionan y erosionan la memoria» y que «el precio a pagar es comprensión, precisión y complejidad» (Huyssen 2004, 4-5). Como en la supresión de la identidad política de los desaparecidos en el Nunca más, donde la figura de la víctima inocente apolítica permitió, inicialmente, la difusión y recepción de los relatos sobre el terrorismo 
de Estado. Pero esta era una simplificación que una nueva generación de historiadores (también de hijos y nietos) interesados en el concepto de la "posmemoria" estaban decididos a cuestionar.

La exploración de los otros aspectos de la humanidad de las víctimas choca con los olvidos institucionalizados que forman parte activa de las políticas de memoria. En el caso de Camino a Auschwitz, este aspecto escondido es el de la sexualidad. Así, logra reconocer a Paie como una prostituta (suka) durante sus últimos años de vida, alude al despertar homosexual de Berl junto con otros miembros de la Organización de Combatientes Judíos y revela el desarrollo de la relación entre Luba y Eichmann a través de un abrazo y un roce de la mano rarificados, mostrando que los desbordes afectivos de asco y miedo iniciales pueden reconfigurarse tomando direcciones inesperadas. «Lo que yo hice fue explorar en los lados oscuros, en las zonas débiles de mis personajes. Una especie de mancillar a los héroes», admite Gorodischer (Dell'Isola 2015). $\mathrm{Su}$ «heroísmo de zonas grises» (Gorodischer en Dell'Isola 2015), entonces, contribuye a una necesaria desmitificación.

Desde mediados de los setenta, la literatura argentina ensaya un «acercamiento a la realidad de forma alusiva y simbólica» (Wamba Gaviña 2015,11). Existe una orientación narrativa que suele asimilar las experiencias de persecución política de la dictadura y del régimen nazi, de manera que «el exilio compulsivo o el exterminio conforman el mismo proceso dentro del imaginario argentino» (Wamba Gaviña 2015, 12). Esta historieta también se ubica en dichas coordenadas. La revisión de los símbolos, la experimentación estilística y la fidelidad documental se combinan para, más que una actualización, dar una nueva memoria del pasado.

Camino a Auschwitz y otras historias de resistencia consiste en un registro de hechos verídicos y del intento de construir una memoria histórica permeada por las preguntas de las nuevas generaciones de familiares de víctimas del terror. En un nivel metanarrativo, nos permite comprobar que la adhesión a la reversión del adagio adorniano por Huyssen no garantiza que la siempre renovada tarea de narrar (y de leer) nos resulte hoy más fácil. 


\section{Bibliografía}

Dell'Isola, Silvina. 2015. «Una manera distinta de contar el horror». La Nación, 12 jul. http://www.lanacion.com.ar/1809343-una-manera-distinta-de-contar-el-horror.

Gorodischer, Julián. 2015. «La realidad en comic». Perfil, 20 jun. http://noticias.perfil. com/2015/06/20/la-realidad-en-comic/.

Huyssen, Andreas. 2000. «Of mice and mimesis. Reading Spiegelman with Adorno». New German Critique 81 (otoño): 65-82.

- 2004. «Resistencia a la Memoria: los usos y abusos del olvido público». Conferencia presentada en el XXVII Congresso Brasileiro de Ciências da Comunicação, PUC-RS (Porto Alegre), agosto-septiembre.

Wamba Gaviña, Graciela. 2015. «Memoria de inmigración y holocausto en la generación de los nietos. Julián Gorodischer "Camino a Auschwitz y otras historias de resistencia”». Conferencia presentada en el I Congreso Universitario de Historietas, Universidad Nacional de La Plata (Argentina), noviembre. 